\title{
Heterosynaptic Scaling of Developing GABAergic Synapses: Dependence on Glutamatergic Input and Developmental Stage
}

\author{
Yan Liu, ${ }^{1}$ Li I. Zhang ${ }^{1,3}$ and Huizhong W. Tao ${ }^{1,2}$ \\ ${ }^{1}$ Zilkha Neurogenetic Institute and Departments of ${ }^{2}$ Ophthalmology and ${ }^{3}$ Physiology and Biophysics, Keck School of Medicine, University of Southern \\ California, Los Angeles, California 90033
}

\begin{abstract}
A proportionality or balance between coactivated excitatory and inhibitory inputs is often observed for individual cortical neurons and is proposed to be important for their functions. This feature of neural circuits may arise from coordinated modulation of excitatory and inhibitory synaptic inputs, a mechanism that remains unknown. Here, in vivo whole-cell recordings from tectal neurons of young Xenopus tadpoles reveals activity-dependent bidirectional modifications of GABAergic inputs. At early developmental stages when GABAergic inputs dominate visually evoked responses, repetitive visual stimulation leads to long-term depression of GABAergic inputs. At later stages when convergent glutamatergic inputs are much stronger, long-term potentiation (LTP) of GABAergic inputs is induced. The polarity of GABAergic plasticity depends on the ratio between the magnitude of coactivated glutamatergic and GABAergic inputs (E/I ratio) to the tectal cell: LTP is induced only when the E/I ratio is above a threshold, and the level of LTP correlates linearly with the logarithm of the $E / I$ ratio. The induction of LTP requires the activation of postsynaptic NMDA receptors, as well as presynaptic TrkB signaling likely through retrograde BDNF (brain-derived neurotrophic factor) and is achieved by overcoming a predominant depression process mediated by NMDA receptors on the presynaptic GABAergic neurons. Our results indicate that the strength of developing GABAergic synapses can be scaled in accordance to coactivated convergent glutamatergic input. This mechanism may contribute to the formation of functional neural circuits with correlated excitatory and inhibitory inputs.
\end{abstract}

Key words: balanced excitation and inhibition; GABAergic modulation; plasticity; development; NMDA receptors; BDNF; visual system; optic tectum

\section{Introduction}

Nervous system function requires that neurons remain responsive to stimuli over a broad dynamic range. This requires a delicate balance between excitation and inhibition that a cell receives (Shadlen and Newsome, 1994; Salinas and Sejnowski, 2000; Turrigiano and Nelson, 2004). There are salient examples of functional balance of excitation and inhibition in single cortical neurons. In the prefrontal cortex, persistent network activity during "up" states is maintained by proportional and dynamically well balanced excitatory and inhibitory conductances (Shu et al., 2003; Haider et al., 2006). In the cat primary visual cortex, visually evoked excitatory and inhibitory conductances are balanced exquisitely in neurons at all locations within the orientation map. This balance is thought to be sufficient for generating spike responses that are sharply tuned to orientations (Marino et al., 2005). Similarly, in the rat primary auditory cortex, excitatory and inhibitory synaptic inputs exhibit identical tone-frequencyspecific receptive fields (Wehr and Zador, 2003; Zhang et al., 2003; Tan et al., 2004), with excitatory and inhibitory synaptic conductances exhibiting a strong linear correlation (Zhang et al., 2003). The correlated inhibitory input may serve to increase the

\footnotetext{
Received Jan. 27, 2007; revised March 29, 2007; accepted April 11, 2007.

We thank Dr. Jonah Chan for very helpful discussion and Dr. Sarah Bottjer for comments on this manuscript.

Correspondence should be addressed to Huizhong W. Ta0, 1501 San Pablo Street, Zilkha Neurogenetic Institute 439, Los Angeles, CA 90033. E-mail: hta0@usc.edu.

DOI:10.1523/JNEUROSCI.0376-07.2007

Copyright $\odot 2007$ Society for Neuroscience $\quad$ 0270-6474/07/275301-12\$15.00/0
}

temporal precision of spike responses (Wehr and Zador, 2003). It was also shown in vitro that the number of excitatory and inhibitory synapses maintains a constant ratio across individual dendrites, resulting in constant compound synaptic potential at individual dendritic branches (Liu, 2004).

Despite the importance of the functional balance of excitatory and inhibitory inputs, little is known about how this important feature of neural circuits arises during development. The formation of neural circuits with correlated excitatory and inhibitory inputs requires a coordinated modulation of two inputs activated by the same sensory stimulus. Homeostatic plasticity (Turrigiano et al., 1998; Liu, 2004; Hartman et al., 2006) can regulate the relative strength of excitatory and inhibitory synapses so as to keep relatively stable firing rates of neurons. However, this form of plasticity is thought to operate globally and may not achieve pathway-specific modulation (Turrigiano and Nelson, 2004). In the developing Xenopus retinotectal system, it was observed in individual tectal neurons that glutamatergic and GABAergic synaptic inputs activated by the same visual stimulus exhibit increasing linear correlation in their strengths during development, resulting in a progressive matching of the topography of excitatory and inhibitory synaptic receptive fields (Tao and Poo, 2005). This prompts us to test the hypothesis that developing GABAergic synapses can be modulated in accordance with the strength of coactivated convergent glutamatergic input through activitydependent mechanisms. The impact of glutamatergic input on GABAergic plasticity is unclear, because previous studies have 
often targeted either unitary inhibitory responses between pairs of neurons or pharmacologically isolated inhibitory responses (Gaiarsa et al., 2002). We applied in vivo whole-cell recordings to tectal neurons in Xenopus tadpoles and examined changes of GABAergic synaptic inputs induced by visual stimuli. Under these physiological conditions, we found that GABAergic plasticity in this developing retinotectal system is indeed guided by glutamatergic transmission. Our findings provide potential synaptic plasticity mechanisms that may contribute to the formation of functionally balanced excitatory and inhibitory inputs.

\section{Materials and Methods}

Tadpole preparation. Xenopus laevis tadpoles were raised under room temperature. Tadpoles of Nieuwkoop and Faber stage 40-47 were anesthetized with saline containing $0.02 \%$ tricaine methanesulfonate (MS222), secured by insect pins to a Sylgard-coated dish, and incubated in HEPES-buffered saline containing the following (in mM): $135 \mathrm{NaCl}, 2$ $\mathrm{KCl}, 3 \mathrm{CaCl}_{2}, 1.5 \mathrm{MgCl}_{2}, 10$ HEPES, 10 glucose, and 0.005 glycine, $\mathrm{pH}$ 7.4. The skin was removed, and the brain was split open along the midline to expose the inner surface of the tectum. A low dose of $\alpha$-bungarotoxin $(2 \mathrm{mg} / \mathrm{ml}$ ) was applied to the bath to prevent muscle contraction. Experiments were performed at room temperature, and the bath was constantly perfused with HEPES-buffered saline equilibrated with 100\% oxygen. Chemicals were purchased from Sigma (St. Louis, MO) unless otherwise specified.

Electrophysiology. Tectal cells were patched under visual guidance with an Olympus Optical (Tokyo, Japan) BX50WI microscope. In this study, only cells located in the rostral half of tectum were examined. Micropipettes were made from borosilicate glass capillaries (Kimax; Kimble/ Kontes, Vineland, NJ) and had a resistance in the range of $2-4 \mathrm{M} \Omega$. To avoid ambiguity in data interpretation caused by slow permeability of $\mathrm{Cl}^{-}$in amphotericin perforated patch, whole-cell recordings were applied in the present study to examine $\mathrm{Cl}^{-}$conductance. For recording light-evoked GABAergic currents, the intrapipette solution contained the following (in mM): $120 \mathrm{~K}$-gluconate, $5 \mathrm{NaCl}, 1.5 \mathrm{MgCl}_{2}, 1$ EGTA, 20 HEPES, $2 \mathrm{Na}_{2} \mathrm{ATP}$, and $0.3 \mathrm{GTP}, \mathrm{pH}$ 7.3. For recording miniature GABAergic currents, a cesium-gluconate-based internal solution was used. Whole-cell recordings were made with a patch-clamp amplifier (Axopatch 200B; Molecular Devices, Palo Alto, CA). The whole-cell capacitance was fully compensated, and the series resistance was compensated by $75 \%$ (lag of $100 \mu \mathrm{s}$ ). Signals were filtered at $5 \mathrm{kHz}$ and sampled at $10 \mathrm{kHz}$ using Axoscope software (Molecular Devices). Data accepted for analysis were cases in which the series resistance did not change by $>10 \%$, and input resistance (1-5 G $\Omega$ ) remained relatively constant throughout the experiment. The reversal potential of $\mathrm{Cl}^{-}$currents $(-75$ to $-70 \mathrm{mV}$, determined for individual cells) was sometimes examined at the beginning and end of each experiment by looking at the reversal of spontaneous GABAergic synaptic currents as the holding potential was changed. No significant changes were found in our experiments. When the reversal potential was determined by puffing GABA, neither did we observe any significant change in it after visual conditioning (see Fig. 1I). Reported voltages were corrected for the liquid junction potential (10 $\mathrm{mV}$ ) between the intracellular and extracellular solution.

Visual stimulation. Visual stimulation was delivered through a small liquid crystal display screen, which was mounted on the camera port of the microscope, allowing projection of computer-generated images onto the retina through optics of the microscope (Engert et al., 2002). The contralateral retina was exposed by removing the lens and was flattened and stabilized with a glass coverslip. After patching on a cell, the microscope was moved with manipulators and refocused on the retina for visual stimulation. For whole-field stimulation, the color of the whole screen was changed from total black to total white for $1.5 \mathrm{~s}$. Stimulation software was custom made (in LabView; National Instruments, Austin, TX).

Application of reagents. To puff GABA, pipette containing $1 \mathrm{~mm}$ GABA was placed $\sim 20 \mu \mathrm{m}$ away from the recorded cell. Puffing pressure (6 psi, 30 ms duration) was applied by a Picospritzer (General Valve, Fairfield, $\mathrm{NJ}$ ). For local application of D-2-amino-5-phosphonovaleric acid (DAPV), pipette containing D-APV ( $25 \mathrm{~mm})$ prepared in $\mathrm{pH} 8.0$ solution was placed $\sim 20 \mu \mathrm{m}$ away from the recorded cell. The holding current was $4 \mathrm{nA}$, and the current for iontophoretic ejection was $40 \mathrm{nA}$. Iontophoresis of the control medium without APV did not have any significant effect on the spontaneous or evoked synaptic transmission (data not shown). To obtain NMDA receptor-mediated synaptic currents, retinal ganglion cell (RGC) fibers were electrically stimulated $(0.5 \mathrm{~ms}$ voltage step) through a glass electrode ( $5 \mu \mathrm{m}$ opening) placed on the optic nerve head (Zhang et al., 1998). 6-Cyano-7-nitroquinoxaline-2,3-dione (CNQX) $(10 \mu \mathrm{M})$ and bicuculline methiodide $(10 \mu \mathrm{M})$ were in the bath solution to block AMPA and $\mathrm{GABA}_{\mathrm{A}}$ receptor-mediated responses. NMDA currents were completely blocked when the iontophoresis pipette was $20 \mu \mathrm{m}$ away from the recorded cell (see Fig. $4 \mathrm{~A}$ ) but were not affected when the pipette was $100 \mu \mathrm{m}$ away (data not shown). In addition, iontophoresis of a fluorescence dye (FITC-dextran) under the same condition showed that the affected area was within a radius of $50 \mu \mathrm{m}$. Because the distance between the retina and the contralateral tectum is $>500 \mu \mathrm{m}$, it is unlikely that the retina was affected. For recording miniature IPSCs (mIPSCs) before and after visual conditioning, local pressure ejection of TTX and CNQX was applied to the tectum through a glass pipette ( $5 \mu \mathrm{m}$ opening) placed near the cell. The constant positive pressure was provided by a pneumatic Picopump (World Precision Instruments, Sarasota, FL). With a constant bath perfusion of fresh external solution, light-evoked responses completely recovered within $10 \mathrm{~min}$ after stopping the pressure ejection. To apply BDNF or Trk-IgG (Regeneron Pharmaceuticals, Tarrytown, NY), the preparation was first perfused with bath solution containing $0.1 \%$ BSA for $0.5 \mathrm{~h}$. The reagent was then applied to the bath solution, which was then recycled.

Data analysis. Miniature events were analyzed with Mini analysis software (Synaptosoft, Decatur, GA). Light-evoked responses were analyzed with a custom-written software (LabView). "Off" responses were analyzed in this study because they were usually larger and more consistent. To measure the integrated charge of light-evoked synaptic currents, the onset of evoked responses was first determined according to the average trace of all events in each experiment. The integrated charge was quantified within a $250 \mathrm{~ms}$ window after the response onset for glutamatergic currents and a $800 \mathrm{~ms}$ window for GABAergic currents. Integrated conductance was calculated as integrated charge divided by $\Delta V$, where $\Delta V$ is the difference between the reversal potential of $\mathrm{Cl}^{-}$currents and the command potential. Unpaired $t$ test (two-tail) was performed for statistics unless otherwise specified.

\section{Results}

\section{Repetitive visual stimulation induces bidirectional modifications of GABAergic input}

We examined visually evoked synaptic currents in optic tectal cells of young Xenopus tadpoles by using whole-cell recordings. These tectal neurons receive both glutamatergic inputs from RGCs and GABAergic inputs from local GABAergic interneurons that are driven by RGC inputs (Rybicka and Udin, 1994; Tao and Poo, 2005; Akerman and Cline, 2006; Lien et al., 2006) (Fig. 1A, left). The glutamatergic and GABAergic components of visually evoked synaptic responses were isolated by clamping the membrane potential of the tectal cell at the reversal potential for $\mathrm{Cl}^{-}$ currents $\left(E_{i}\right)(-70$ to $-75 \mathrm{mV})$ and glutamatergic currents $\left(E_{e}\right)$ $(0 \mathrm{mV})$, respectively: at $E_{i}$ to record glutamatergic compound excitatory synaptic currents (cESCs) and at $E_{e}$ to record GABAergic compound inhibitory synaptic currents (cISCs). Consistent with previous observations (Tao and Poo, 2005; Akerman and Cline, 2006; Lien et al., 2006), the outward currents recorded at $E_{e}$ were completely blocked by picrotoxin or bicuculline and thus were mediated by $\mathrm{GABA}_{\mathrm{A}}$ receptors (Fig. $1 \mathrm{~A}$, right). The magnitude of glutamatergic and GABAergic currents evoked by wholefield light stimulation varies over a broad range during these early stages, likely as a result of different maturation stages of the neurons (Fig. 1B) (see Fig. 2D). This provides us an opportunity to examine the relationship between GABAergic synaptic plasticity 
A
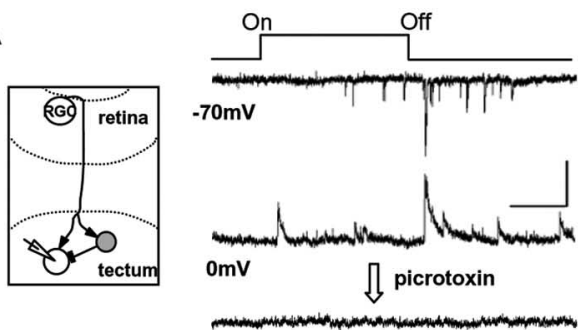

C

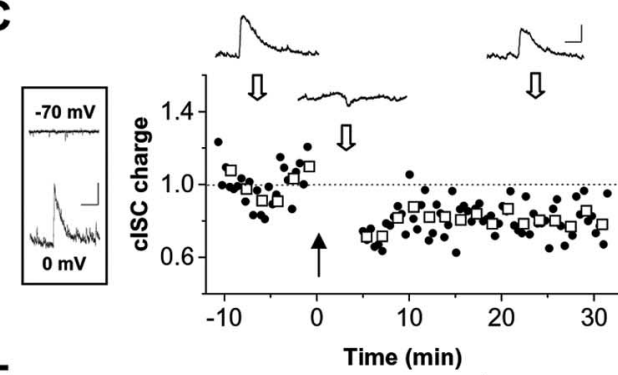

$\mathbf{E}$

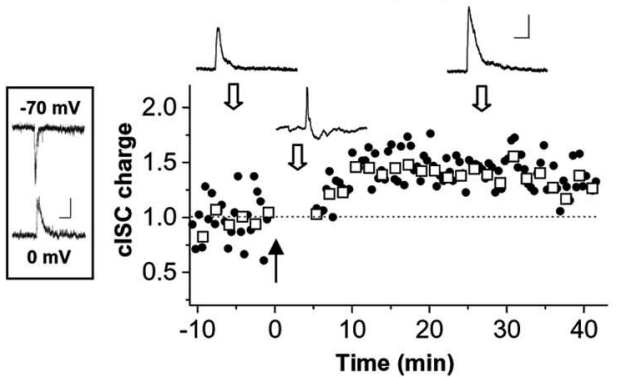

G

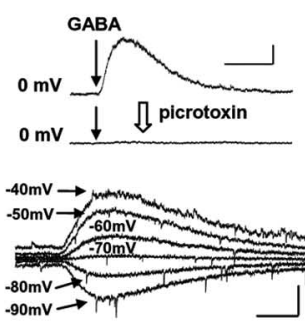

$\mathbf{H}$

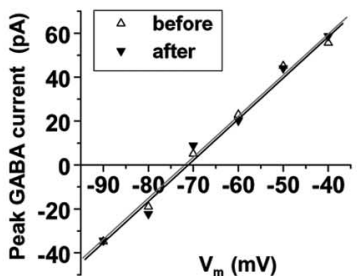

I

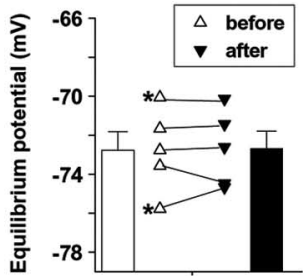

Figure 1. Visual conditioning-induced bidirectional plasticity of GABAergic input. $A$, Left, Schematic diagram of a feedforward inhibitory circuit in the tectum. Local GABAergic interneurons (gray circle) receive excitatory drive from RGC inputs and make connections with other tectal neurons. Right, Example synaptic responses in a stage 43 tectal cell, each evoked by a $1.5 \mathrm{~s}$ whole-field light stimulus (represented by dark lines on top; On, change of screen color from black to white; Off, return to black) and recorded at $V_{h}$ of -70 and $0 \mathrm{mV}$, respectively. Bottom trace, Response recorded at $0 \mathrm{mV}$ was blocked after bath application of $100 \mu \mathrm{m}$ picrotoxin. Calibration: 50 pA, $500 \mathrm{~ms}$. B, Average integrated charges of whole-field light-evoked cISC and CESC at different developmental stages (stg.) ( $n=12,14,17,6$ for groups $1-4)$. There is a significant decrease in cISC and a significant increase in cESC from stage 40 - 41 to $45-46(p<0.05)$. C, Left, In this example cell of a stage $40-41$ tadpole, visual stimulus elicited a large cISC when recorded at $0 \mathrm{mV}$ (bottom) but no significant glutamatergic response when recorded at $-70 \mathrm{mV}$ (top). Calibration: 60 pA, 500 ms. Right, Normalized integrated charge of cISC before and after visual conditioning (marked by the black arrow) in the same cell. Each data point was normalized to the control value (averaged during the 10 min period before the conditioning). Circles represent each sampled CISC. Squares represent average value for four consecutive cISCS. Traces on top are average responses (from 8 trials) before, during, and after conditioning, at times indicated by the open arrows. Calibration: 50 $\mathrm{pA} / 20 \mathrm{mV}, 250 \mathrm{~ms}$. D, Summary of 13 similar experiments (filled symbols). Data represent mean \pm SEM. Open symbols are for summary of nine control experiments in which cISCS were monitored continuously at $V_{h}$ of $0 \mathrm{mV}$ and at $0.04 \mathrm{~Hz}$. E, Left, Lightevoked CESC and CISC (single trial) in an example cell at stage $45-46$, recorded at -70 and $0 \mathrm{mV}$, respectively. Calibration: $40 \mathrm{pA}$, $200 \mathrm{~ms}$. Right, Normalized integrated charge of clSC for the same cell before and after conditioning. Calibration: $40 \mathrm{pA} / 12 \mathrm{mV}, 250$ ms. $\boldsymbol{F}$, Summary of 12 similar experiments. $\boldsymbol{G}$, Top, Currents evoked by puffing GABA (indicated by the arrow) were completely blocked by picrotoxin ( $100 \mu \mathrm{M})$. Calibration: 40 pA, $500 \mathrm{~ms}$. Bottom, GABA-evoked currents recorded at six different membrane potentials in an example cell. Each trace was average from three trials. Calibration: 30 pA, $200 \mathrm{~ms}$. $\boldsymbol{H}$, Current-voltage relationship for GABA-evoked currents before and $10-15$ min after visual conditioning for the same cell. Data point represents average value of five to eight trials. Lines are best fits using linear regression. Black line is for after conditioning. The reversal potential for $\mathrm{Cl}^{-}$ currents is taken as the $x$-intercept of the best-fit line. $I$, Measured $\mathrm{Cl}^{-}$equilibrium potentials in five experiments. The asterisk indicates the cell that exhibited a dominating CISC. Bars are for mean \pm SEM. and the level of convergent glutamatergic input during the early formation of functional visual circuits.

To test activity-induced modification of GABAergic input, repetitive visual stimulation or "visual conditioning" was applied. To understand the impact of convergent glutamatergic input, we compared effects of visual conditioning between two arbitrarily separated groups of tectal neurons: those with weak and those with strong glutamatergic input. As shown in a representative cell recorded from a stage 40-41 tadpole, whole-field stimulation applied to the retina (see Materials and Methods) evoked a large cISC in this cell when recorded at $0 \mathrm{mV}$, whereas cESC recorded at $-70 \mathrm{mV}$ was barely detectable (Fig. 1C, left). This type of tectal cell response with a dominating cISC was frequently observed at early stages $(40-43)$ after RGC axons first arrive in the tectum (stage 39) and may reflect an immature stage of the tectum when functional glutamatergic synapses are yet to be established in many tectal neurons (Wu et al., 1996). In the meantime, it suggests that glutamatergic synapses made by RGC inputs on GABAergic interneurons develop much earlier than those on glutamatergic tectal neurons. cISCs evoked by whole-field light stimulation were first monitored at a low testing frequency of $0.04 \mathrm{~Hz}$ (Fig. $1 C$, right). After acquiring a stable baseline, the recording was switched to current-clamp mode, and repetitive light stimulation at a higher frequency $(0.4-0.5 \mathrm{~Hz}$ for 100 times) was applied. Because the reversal potential of $\mathrm{Cl}^{-}$currents in our experimental condition was close to the resting membrane potential of the recorded tectal neurons $(-60$ to $-70 \mathrm{mV})$, in cells that exhibited weak or nonsignificant glutamatergic responses, light stimulation caused little change or sometimes small hyperpolarization of the membrane potential (Fig. $1 C$, right panel, top middle trace). After visual conditioning, the recording was switched back to voltage-clamp $(0 \mathrm{mV})$ mode to continue the monitoring of visually evoked cISCs. The integrated charge of cICSs (see Materials and Methods) was decreased compared with the control period before conditioning (Fig. 1C, right). A summary of 13 similar experiments showed an average $24.7 \pm 4.5 \%$ (mean \pm SEM) reduction in cISC charges at 25-30 min after the conditioning (Fig. $1 D$, filled symbols), whereas in the absence of visual conditioning, cISCs monitored at the low test frequency were stable over the course of at least $45 \mathrm{~min}$ recording (Fig. $1 \mathrm{D}$, open symbols). These data demonstrate that, in 
the absence of strong convergent glutamatergic input, visual conditioning reduced visually evoked GABAergic responses, consistent with a recent report on visually induced depression of GABAergic input (Lien et al., 2006).

Conversely, when tectal cells exhibited much stronger visually evoked glutamatergic responses, often found at more mature stages (Fig. 1B), conditioninginduced modification of cISCs was switched to potentiation. In a representative cell recorded from a stage 45-46 tadpole, a large cESC evoked by light stimulation was observed when recorded at -70 $\mathrm{mV}$ (Fig. 1E, left). Under current clamp, this cESC elicited robust membrane depolarization and spikes immediately before the small hyperpolarization generated by the GABAergic response (Fig. $1 E$, right panel, top middle trace). After visual conditioning, the integrated charge of cISC in this cell was markedly increased (Fig. $1 E$, right). Twelve similar experiments showed an average $27.4 \pm 5.1 \%$ (mean \pm SEM) increase in cISC charges (Fig. $1 F$ ). Although membrane depolarization was observed during conditioning in all cases $(12.8 \pm 5.5 \mathrm{mV})$, only a small portion of cells $(33 \%)$ exhibited consistent spikes ( $>50 \%$ probability across 100 trials), suggesting that postsynaptic spiking is not necessary for the induction of potentiation of cISC (Maffei et al., 2006). Similar repetitive visual stimuli have been shown to induce a potentiation of glutamatergic input in a postsynaptic spikingdependent manner (Zhang et al., 2000; Lien et al., 2006). Our present result suggests that potentiation of GABAergic input can be associated with, but is independent of, potentiation of convergent glutamatergic input.

Repetitive activity may cause a positive change in the chloride equilibrium potential $\left(\mathrm{E}_{\mathrm{Cl}-}\right)$, which can lead to an apparent change of synaptic currents without changing synaptic conductance (Woodin et al., 2003; Fiumelli et al., 2005). By examining the current-voltage relationship of GABA-evoked currents in tectal cells (see Materials and Methods), we examined the $\mathrm{E}_{\mathrm{Cl}-}$ before and after applying visual conditioning (Fig. 1G). The currents evoked by puffing GABA were completely blocked by picrotoxin (Fig. $1 G$, top) and thus were mediated by GABA receptors, similar to light-evoked cISCs. We did not observe any significant changes in the reversal potential of GABA-evoked currents after visual conditioning in cells with either type of response (Fig. $1 H, I$ ). Therefore, under our whole-cell recording conditions, the observed changes in GABAergic currents are attributable to changes in synaptic conductance.

\section{Dependency of GABAergic plasticity on the strength of glutamatergic input}

To more quantitatively determine the relationship between cISC plasticity and the magnitude of coactivated convergent glutamatergic input, we plotted the percentage change (color coded) in cISC after conditioning as a function of integrated charge of cESC and cISC for all of the cells recorded in stage 40-47 tadpoles (Fig. $2 A)$. The polarity of GABAergic plasticity appears to depend on
C

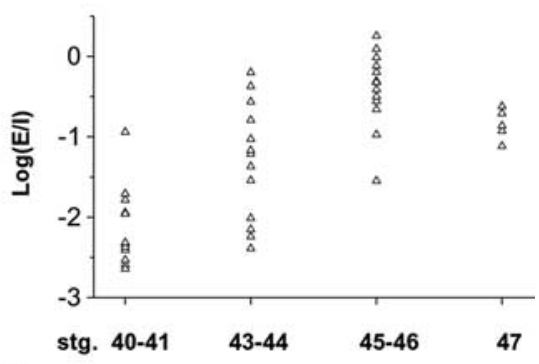

D

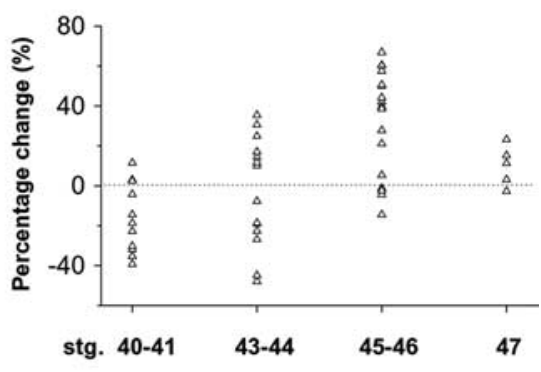

Figure 2. Dependence of cISC plasticity on the level of coactivated convergent cESC and developmental stage (stg.). $\boldsymbol{A}$, The mental stages. Each data point represents one cell. Significant difference was observed between each pair of neighboring age groups $(p<0.01)$. D, Distribution of percentage changes in cISC charge after conditioning in the same group of cells.

the magnitude of coactivated convergent glutamatergic input: cISCs with associated cESC charges smaller than $1 \mathrm{pC}$ mostly underwent depression, whereas those with cESC charges larger than $2 \mathrm{pC}$ mostly exhibited potentiation. In addition, for cells with similar cESC charges, the potentiation level is reduced with an increase of cISC charges (Fig. 2A), suggesting that it may in fact depend on the ratio between the magnitude of cESC and cISC ( $E / I$ ratio). This becomes clearer when the level of plasticity is plotted against the logarithm of the $E / I$ ratio, i.e., $\log (E / I)$ (Fig. $2 B)$. There was an apparent transition point, above which cISCs exhibited conditioning-induced potentiation of various levels. Interestingly, the extent of potentiation exhibited a linear correlation with $\log (E / I)$ (correlation coefficient, $r=0.71 ; p<0.001$ in linear regression), whereas there was no apparent correlation between the extent of depression and the $E / I$ ratio $(r=0.08 ; p=$ $0.76)$. The best-fit line calculated for the potentiation level$\log (E / I)$ relationship using linear regression (Fig. $2 B$, red line) has an $x$-intercept of -1.3 . We took this value as the estimated threshold level of $\log (E / I)$ for the induction of potentiation. Our data demonstrate that, under certain sensory stimuli, the strength of the GABAergic inputs can be upregulated according to the relative magnitude of coactivated convergent glutamatergic inputs.

\section{Dependency of GABAergic plasticity on developmental stage}

At stages before 43, recorded tectal neurons usually have weak excitatory inputs that become stronger as tadpoles mature (Fig. $1 B)$. This suggests that the polarity and level of GABAergic plasticity may also depend on developmental stage. To demonstrate this relationship, the $E / I$ ratio and the level (positive or negative) of GABAergic plasticity for the same group of neurons were plot- 

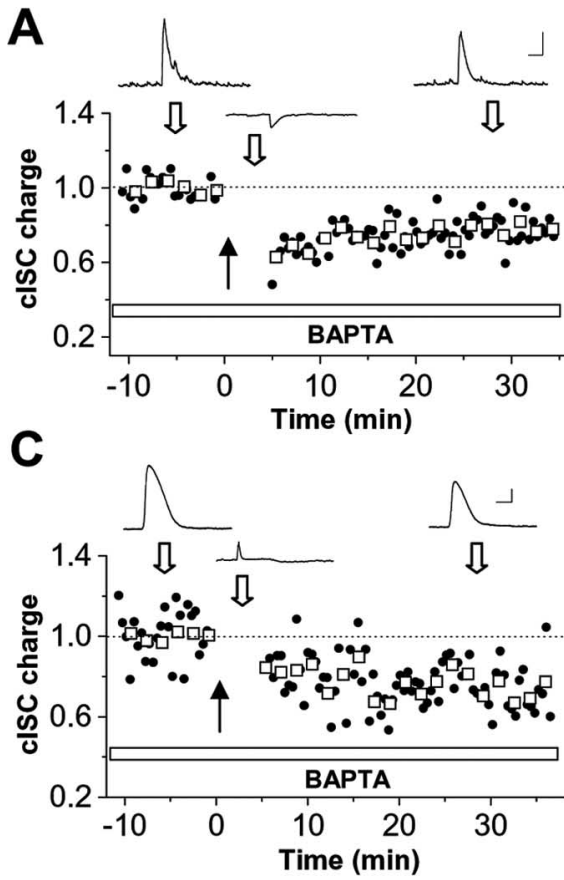

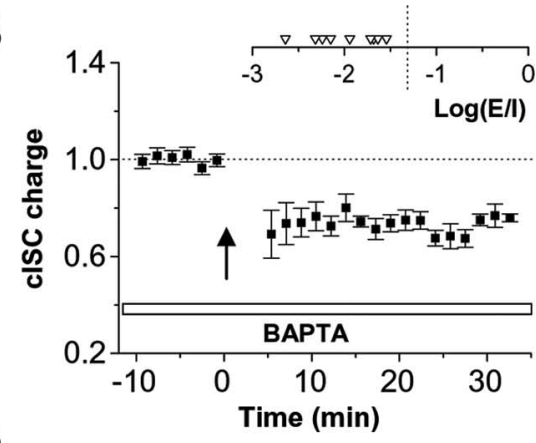

D

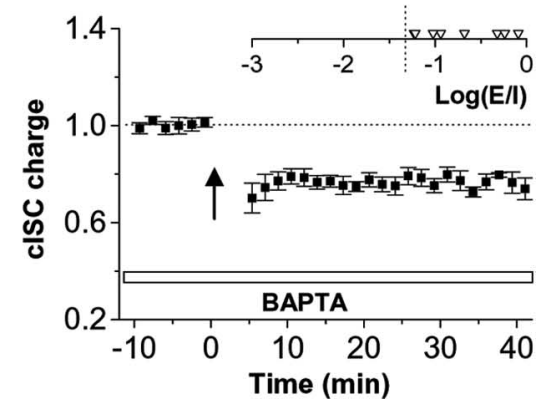

Figure 3. Differential dependence of $\mathrm{CISC}$ plasticity on postsynaptic $\mathrm{Ca}^{2+}$ increase. $A$, An example experiment in which $10 \mathrm{~mm}$ BAPTA was loaded into a tectal cell, which had a dominating cISC. Data are presented as in Figure 1. Calibration: 100 pA/20 mV, 250 ms. $\boldsymbol{B}$, Summary of nine experiments. Inset shows the distribution of $\log (E / /)$ values in these cells. The dotted vertical line represents the estimated threshold $\log (E / I)$ value for the induction of potentiation. $\boldsymbol{C}, \boldsymbol{D}$, The effect of BAPTA loading in cells that belong to the potentiation group. Data are presented as in $\boldsymbol{A}$ and $\boldsymbol{B}$. Calibration: $50 \mathrm{pA} / 20 \mathrm{mV}, 200 \mathrm{~ms}$.

ted according to their developmental stages (Fig. 2C,D). Although there is often a large variation in the $E / I$ ratio from one age group (likely because of the differential maturation status of cells even in the same tectum), the developmental trend is clear: it increases initially and reaches a peak at stage 45-46 and then appears to reduce at 47 (because of technical limitations, the oldest stage examined for long-term plasticity study is stage 47). Consistent with the developmental change in the $E / I$ ratio, cISC plasticity is initially dominated by depression. With the developmental progression, potentiation becomes more prevalent, and the level of potentiation increases. After reaching a peak at stage 46 , the level of potentiation is reduced at older stages. The dependence of GABAergic potentiation on the developmental stage further supports the role of glutamatergic input in guiding GABAergic modification.

\section{GABAergic potentiation depends on a postsynaptic} induction mechanism

The induction of potentiation of cISC may be mediated through a postsynaptic mechanism, because it depends on strong convergent glutamatergic inputs. We first examined the involvement of postsynaptic $\mathrm{Ca}^{2+}$ increase, which has been shown to be necessary for many forms of long-term plasticity of inhibitory transmission (Llano et al., 1991; Kano et al., 1992; Komatsu, 1996; Morishita and Sastry, 1996; Aizenman et al., 1998; Caillard et al., 1999; Holmgren and Zilberter, 2001; Patenaude et al., 2003). To effectively block $\mathrm{Ca}^{2+}$ increase in the recorded tectal cell, we included $10 \mathrm{~mm}$ BAPTA in the intrapipette solution (Tao et al., 2001). The defined relationship between the polarity of cISC plasticity and the relative strength of cESC (Fig. $2 B$ ) allows us to categorize cells into "depression" or "potentiation" groups. In our analysis, we used a $\log (E / I)$ value of -1.3 as the separation point between the two groups. For a group of cells with dominat- ing cISCs [depression group, with the $\log (E / I)$ value lower than -1.3 ], loading the postsynaptic cell with BAPTA had no effect on the normal induction of depression (Fig. $3 A, B$ ). In contrast, for tectal cells that belonged to the potentiation group [with the $\log (E / I)$ value higher than $-1.3]$, BAPTA completely blocked the induction of potentiation, and instead depression was induced (Fig. 3C,D). Thus, the induction of potentiation of cISC depends on an increase in postsynaptic $\mathrm{Ca}^{2+}$ level, whereas depression does not. In addition, the switch of polarity of cISC plasticity after BAPTA loading implies that potentiation is achieved through competing with a predominant depression process. When potentiation is prevented, the depression is revealed.

\section{The dependence on NMDA receptors}

NMDA receptors have been implicated in some forms of GABAergic synaptic plasticity (Komatsu and Iwakiri, 1993; McLean et al., 1996; Wang and Stelzer, 1996; Lu et al., 2000; Ouardouz and Sastry, 2000). We next investigated whether NMDA receptor activity is required for the potentiation of the GABAergic inputs. Because RGCs also exhibit NMDA receptormediated synaptic currents ( $\mathrm{Du}$ and Poo, 2004), to avoid possible interference with retinal circuits, we locally applied D-APV, a specific blocker of NMDA receptors, to the tectal region by iontophoresis (see Materials and Methods). As shown in Figure $4 \mathrm{~A}$, with CNQX and bicuculline present in the bath solution, NMDA receptor-mediated synaptic currents evoked by electrical stimulation of optic fibers can be readily recorded in tectal neurons. Immediately after iontophoresis of APV around the recorded cell, the NMDA synaptic current was completely blocked. The effect of APV was reversible: the NMDA current recovered within minutes after stopping the iontophoretic ejection of APV when fresh bath solution was constantly perfused. For a depression group of cells, iontophoresis of APV during the conditioning period effectively prevented the induction of depression (Fig. $4 B, C$ ), consistent with a recent report (Lien et al., 2006). Because depression does not require an increase in postsynaptic $\mathrm{Ca}^{2+}$ for its induction (Fig. $3 B$ ), its dependence on NMDA receptors suggests that this form of plasticity requires activation of those NMDA receptors located at the presynaptic GABAergic neurons.

For a potentiation group of cells, APV also blocked the induction of potentiation (Fig. $4 D, E$ ). In contrast to the result observed with BAPTA loading, there was no switch to depression, consistent with the result that APV also blocked the induction of depression. The requirement of both postsynaptic $\mathrm{Ca}^{2+}$ increase and activation of NMDA receptors suggests that the glutamatergic input-dependent potentiation of the GABAergic input was induced through a postsynaptic NMDA receptor-dependent mechanism. This was further confirmed by loading the tectal cell with a use-dependent NMDA receptor blocker, MK-801 [(5S,10R)-(+)-5-methyl-10,11-dihydro-5H-dibenzo [a,d] cyclohepten-5,10-imine maleate] (1 mM) (Berretta and Jones, 1996; Lien et al., 2006). Because MK-801 can only have effects when the cells are depolarized ( $V_{\mathrm{h}}$ of $0 \mathrm{mV}$ in our experiments) 
and the leakage from the patch pipette was cleared effectively by constantly perfusing fresh bath solution, the postsynaptic loading of MK-801 could only affect postsynaptic NMDA currents. Similar to the effect of postsynaptic loading of BAPTA, this treatment prevented the induction of potentiation and changed the polarity of plasticity to depression (Fig. $4 F, G$ ).

The requirement of activation of postsynaptic NMDA receptors for the GABAergic potentiation suggests that glutamatergic inputs play a role in both depolarizing the cell and supplying glutamate, both of which are necessary for the activation of NMDA receptors (Mayer et al., 1984; Nowak et al., 1984). As a test of this idea, repetitive depolarizing current pulses $(0.1 \mathrm{nA}, 200 \mathrm{~ms})$ were injected into the tectal cell, and three to four spikes were elicited by each current pulse. This direct depolarization of the tectal cell alone without coupling visual stimuli was not sufficient to induce any change of cISCs (Fig. $4 H, I$, DP). Moreover, for a depression group of cells exhibiting dominating GABAergic responses, visual conditioning coupled with depolarizing current injection did not change the polarity of plasticity, and cISCs still exhibited depression (Fig. 4 H, DP+L). Conversely, for a potentiation group of cells, visual conditioning with each stimulus coupled with hyperpolarizing current injection (1-10 nA, $200 \mathrm{~ms}$ ) that prevented membrane depolarization induced depression instead of potentiation (Fig. 4I, HP+L). Together, these data support the idea that glutamatergic input during repetitive visual stimulation not only drives postsynaptic depolarization but also provides glutamate to activate abundant postsynaptic NMDA receptors, resulting in the potentiation of convergent GABAergic input.

\section{Potentiation and depression are associated with changes in presynaptic release}

Because the recorded GABAergic currents are disynaptic (Tao et al., 2005; Akerman and Cline, 2006; Lien et al., 2006), the observed cISC plasticity can be simply explained by a change in the excitatory drive of presynaptic GABAergic neurons. To determine whether the observed cISC plasticity was associated with changes in GABAergic synapses made on the recorded tectal neurons, we examined mIPSCs before and after induction of cISC plasticity (Fig. $5 \mathrm{~A}, \mathrm{C}$ ). Compared with control experiments in which no visual conditioning was applied, conditioning-induced potentiation of cISC was accompanied by an increase in mIPSC frequency, whereas decreased mIPSC frequency was observed after induction of depression (Fig. $5 B, D, E$ ). The amplitude of mIPSCs was not changed significantly after either potentiation or depression (Fig. 5E).

Because the strength of action-potential-dependent synaptic transmission may not always be in parallel with the frequency of each bar. ${ }^{*} p<0.01$

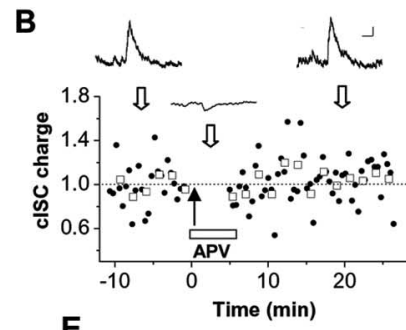

C

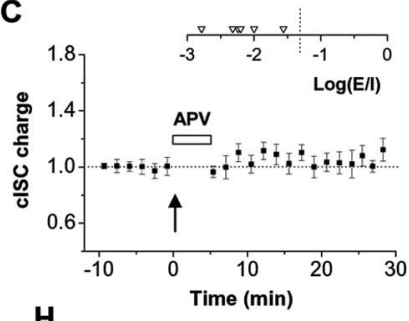

H
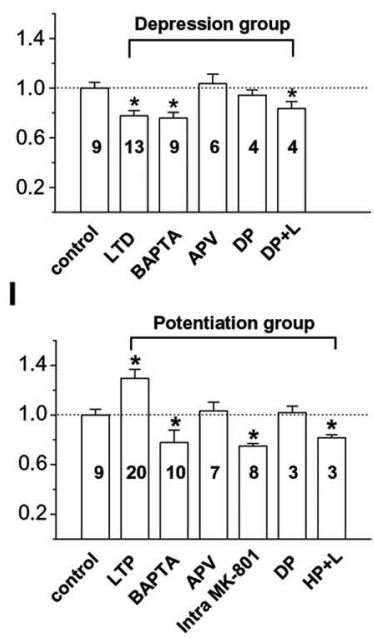

Figure 4. Depression and potentiation of CISCS depend on NMDA receptors located at presynaptic and postsynaptic cells,

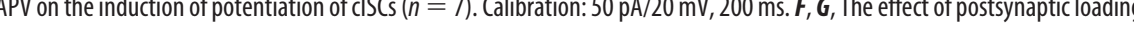
stimuli with each coupled with a $200 \mathrm{~ms}$ hyperpolarizing current injection. The number of experiments in each group is labeled in

miniature synaptic currents, we further analyzed electrically evoked IPSCs after induction of plasticity with high-frequency stimulation. With CNQX present in the bath solution, a concentric bipolar electrode placed in the deep layers of the rostral tectum (Lien et al., 2006) could evoke monosynaptic IPSCs, which represent inputs from directly activated GABAergic interneurons. Under this condition, theta-burst stimulation (TBS), a type of burst activity that likely occurs under visual stimuli (Tao et al., 2001), induced depression of these GABAergic synapses (Fig. $6 A, B)$, consistent with previous results (Lien et al., 2006). The increase in both the coefficient of variance $(\mathrm{CV})$ and the failure rate after induction (Fig. 6C,D) supports that this depression is attributable to a reduction of presynaptic release probability (Manabe et al., 1993). Our control experiments indicate that the $\mathrm{CV}$ analysis is a reliable assay for reduced presynaptic release, because $\mathrm{CV}$ was increased when external $\mathrm{Ca}^{2+}$ concentration was lowered but was unaffected when only postsynaptic sensitivity was reduced by bicuculline (Fig. 6C).

When CNQX was washed out, evoked EPSCs were also observed, which primarily represent activated RGC inputs. TBS ap- 
A

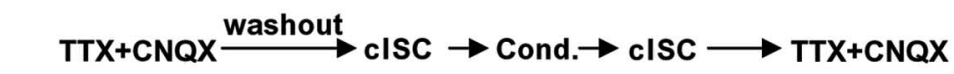

B
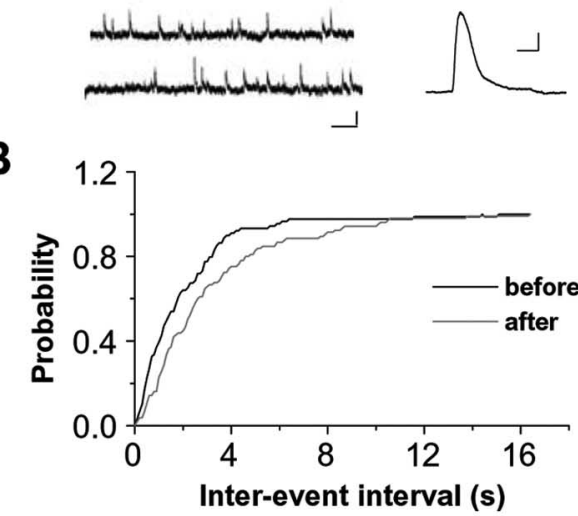

C

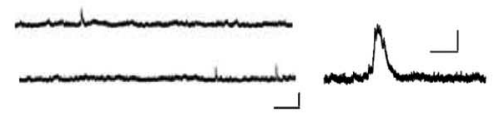

D

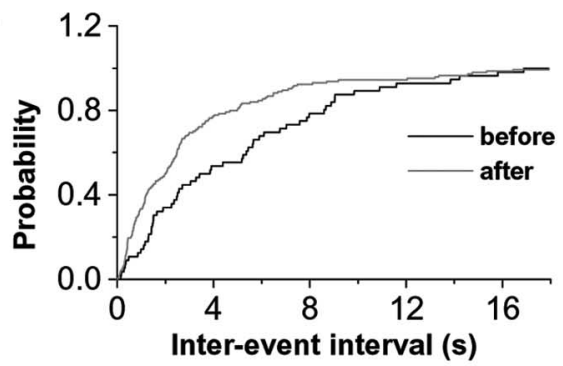

E

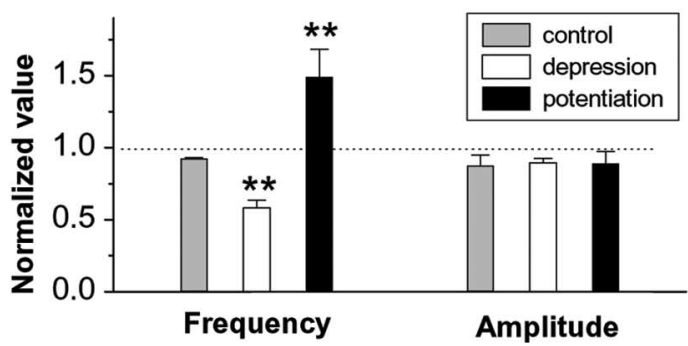

Figure 5. Depression and potentiation of cISCS are associated with changes in presynaptic release. $\boldsymbol{A}$, Top, Experimental procedure for monitoring mIPSCs before and after visual conditioning (Cond.). The recording session is $8-10 \mathrm{~min}$ for $\mathrm{mIPSCs}$ and 5-10 min for cISCS. The washout session is $10 \mathrm{~min}$. Bottom, Example traces for recording from a stage 42 cell $\left(V_{h}\right.$ of $\left.0 \mathrm{mV}\right)$ of $\mathrm{mIPSCS}$ and light-evoked cISCs (average from 8 trials) before and after visual conditioning. Calibration: left, 10 pA, 500 ms; right, 50 pA, $200 \mathrm{~ms}$. $\boldsymbol{B}$, Cumulative distribution of interevent intervals and amplitudes of mIPSCs recorded before and after the induction of depression in the cell. $\boldsymbol{C}, \boldsymbol{D}$, An example experiment (stage 45) in which potentiation of cISC was induced. Data are presented as in $\boldsymbol{A}$ and $\boldsymbol{B}$. Calibration: left, 10 pA, $500 \mathrm{~ms}$; right, 20 pA, $200 \mathrm{~ms}$. $\boldsymbol{E}$, Summary of normalized mIPSC frequency and amplitude after visual conditioning. In control experiments, no conditioning was applied. Right, Distribution of $\log (E / I)$ values for these three sets of experiments. c, Control; d, depression; $p$, potentiation. ${ }^{* *} p<0.01$.

plied in the absence of CNQX, in contrast, could induce potentiation of monosynaptic IPSCs, which were monitored in the presence of CNQX after TBS (Fig. 6E,F). The decrease in CV and in paired-pulse ratio (PPR) is consistent with an increase in presynaptic release after potentiation, because the control experiment with increased external $\mathrm{Ca}^{2+}$ concentration produced similar changes in CV and PPR (Fig. 6G,H). Together with the changes in the frequency but not the amplitude of mIPSCs, these results suggest that the observed depression and potentiation of the GABAergic input can be attributed, at least partially, to changes in presynaptic GABAergic release.
Potentiation depends on presynaptic TrkB signaling

Because potentiation of cISCs involves a postsynaptic induction mechanism and an increase in presynaptic GABAergic release, a retrograde messenger is necessary for signaling postsynaptic activity back to the presynaptic terminal. BDNF, a candidate retrograde signal, can rapidly modulate GABAergic synaptic strength (Schuman, 1999; Schinder and Poo, 2000). It is also known to be important for the maturation of GABAergic neurons and synapses (Marty et al., 1997; Huang et al., 1999; Jiang et al., 2005; Itami et al., 2007). It has been reported that endogenous BDNF is required for depolarization-induced potentiation of spontaneous GABAergic currents in the developing rat hippocampus (Gubellini et al., 2005). BDNF is expressed in the Xenopus tectum, and its messenger RNA peaks at stage 45/46 (Cohen-Cory et al., 1996). Because neuronal release of BDNF is $\mathrm{Ca}^{2+}$ dependent (Balkowiec and $\mathrm{Katz}, 2002$ ), it is possible that $\mathrm{Ca}^{2+}$ influx through postsynaptic NMDA receptors triggers dendritic release of BDNF, which then leads to potentiation of GABAergic synapses on the same postsynaptic cell. To determine the role of endogenous BDNF and its receptor TrkB, we first tested the effect of blocking TrkB signaling with K252a, a membrane-permeant inhibitor of Trk receptor-mediated protein tyrosine kinase activity (Knusel and Hefti, 1992; Ross et al., 1995). K252a (200 nM) was bath applied at least $30 \mathrm{~min}$ before the onset of recordings. For a potentiation group of cells, this treatment switched the polarity of plasticity to depression (Fig. $7 A, B$ ). To explicitly test the role of TrkB signaling, we preincubated the tadpole preparation in the bath solution containing TrkB-IgG (2 $\mu \mathrm{g} / \mathrm{ml}$ ) for at least $1 \mathrm{~h}$ before the recordings. TrkB-IgG is a fusion protein of the extracellular domain of TrkB and the Fc domain of human IgG and is used as scavenger for extracellular BDNF to prevent activation of endogenous $\operatorname{TrkB}$ receptors (Shelton et al., 1995). Like K252a, TrkBIgG effectively blocked the potentiation of cISCs and revealed an underlying depression (Fig. 7C,D). In contrast, preincubation of TrkC-IgG to sequester the endogenous TrkC ligand neurotrophin 3 had no effect on the normal induction of potentiation (Fig. 7D). These results indicate that activation of endogenous TrkB receptors is required for glutamatergic input-dependent potentiation of cISCs. To further identify whether TrkB receptors of presynaptic or postsynaptic location mediate the potentiation effect, we blocked postsynaptic TrkB receptors by loading the postsynaptic cell with K252a (200 nM). This manipulation had no effect on the normal induction of potentiation (Fig. $7 B$, open symbols), suggesting that potentiation is mediated by presynaptic TrkB recep- 
tors, which is consistent with the associated presynaptic change (Figs. 5, 6).

\section{BDNF potentiates presynaptic GABAergic release}

We next examined the effect of exogenous BDNF on GABAergic transmission. mIPSCs were recorded in the presence of TTX and glutamate receptor blockers CNQX and D-APV. Bath application of BDNF $(100 \mathrm{ng} / \mathrm{ml})$ rapidly increased the frequency of mIPSCs (Fig. $8 A, B, D$ ). Conversely, neither the amplitude of mIPSCs (Fig. 8C,E) nor the time course of mIPSCs was affected (rise time was $1.55 \pm 0.08 \mathrm{~ms}$ before and $1.69 \pm 0.14 \mathrm{~ms}$ after BDNF application, $n=5, p=0.3$, paired $t$ test; decay time constant was $14.1 \pm 0.7 \mathrm{~ms}$ before and $14.8 \pm 0.9 \mathrm{~ms}$ after BDNF, $p=0.24)$. Overall, there was a $29 \pm 6 \%$ increase in mIPSC frequency 10-20 min after the application of BDNF (Fig. 8E). This effect appears to last for at least $30 \mathrm{~min}$ (Fig. $8 \mathrm{D}$ ). The presence of K252a completely abolished this effect (Fig. $8 \mathrm{E}$ ), further suggesting that it was mediated through TrkB receptor signaling. K252a, by itself, had no effect on either the frequency or the amplitude of mIPSCs (frequency, $97 \pm 7 \%$ of control value; amplitude, $96 \pm 4 \%$ of control value; $n=3$ ). The effect of BDNF on mIPSC frequency suggests that BDNF may enhance GABAergic release at these developing synapses by increasing either release probability or the number of functional release sites.

Because there is evidence that spontaneous and evoked vesicular release can be independently regulated (Broadie et al., 1994; Geppert et al., 1994; Schoch et al., 2001), we further examined the effect of BDNF on evoked GABAergic transmission. We found that application of BDNF alone did not change the baseline of monosynaptic IPSCs (Fig. 8F, open symbols). However, when TBS was applied to GABAergic synapses in the presence of BDNF, they became potentiated (Fig. $8 F$, filled symbols), in contrast to being depressed when TBS was applied in the absence of BDNF (Fig. $6 A, B)$. This suggests that only strongly activated GABAergic synapses are susceptible to BDNF-facilitated potentiation. The reduction in CV and PPR after the potentiation indicates that presynaptic changes have occurred (Fig. 8G,H). Together, our results strongly support the role of BDNF and TrkB signaling in mediating visual conditioning-induced GABAergic potentiation.

\section{Discussion}

The major finding of this study is that repetitive visual stimuli can modulate GABAergic input to tectal neurons bidirectionally, with the direction of modification determined by whether there is accompanied strong convergent glutamatergic input. When light-evoked synaptic responses are dominated by GABAergic responses, repetitive stimuli will cause depression of these responses. When GABAergic inputs are coactivated with strong convergent glutamatergic inputs, they will become potentiated, or at least be prevented from depression, after repetitive stimuli.
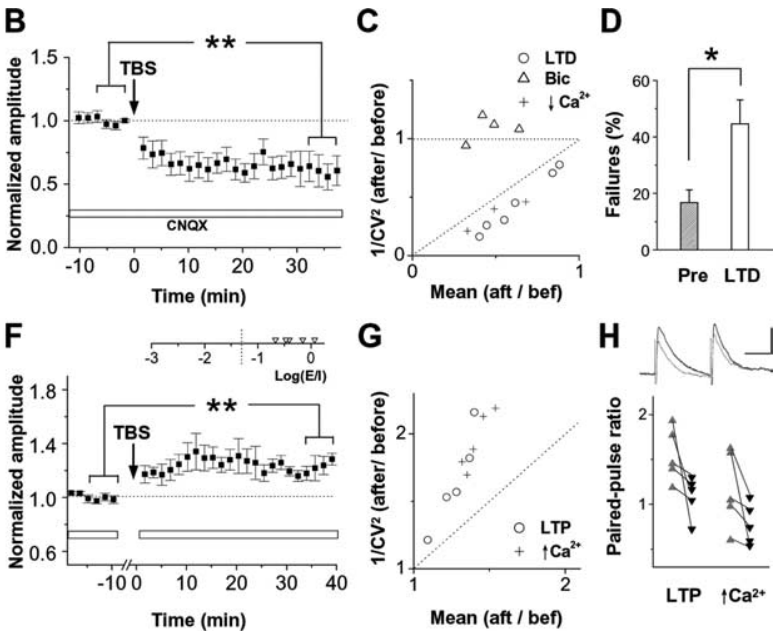

Figure 6. Electrically induced long-term depression (LTD) and long-term potentiation (LTP) of GABAergic synapses. $\boldsymbol{A}$, An example experiment in which long-term depression of monosynaptic IPSCS was induced by TBS (4 pulses at $100 \mathrm{~Hz}$ in one burst, 10 bursts at $4 \mathrm{~Hz}$ ). Electrically evoked IPSCs were sampled $\left(V_{h}\right.$ of $\left.0 \mathrm{mV}\right)$ in the presence of CNQX. Top, Average traces (from 8 trials) 作 when postsynaptic $\mathrm{GABA}_{\mathrm{A}}$ receptors were partially blocked by $0.2 \mu \mathrm{m}$ bicuculline (Bic) and when release probability was reduced by applying low $\mathrm{Ca}^{2+}$ external solution ( $1 \mathrm{~mm} \mathrm{Ca}^{2+}, 3.5 \mathrm{~mm} \mathrm{Mg}^{2+}$ ), respectively. D, Synaptic failure rate before and after the

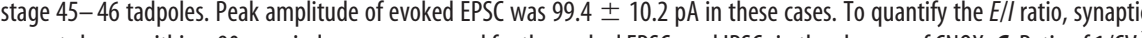
$t$ test) and was $1.16 \pm 0.19$ before and $0.77 \pm 0.10$ after high $\mathrm{Ca}^{2+}(p=0.042)$. Top, Example traces for IPSC (average of 20) before (gray) and after (black) TBS-induced long-term potentiation. Calibration: 20 pA, 50 ms.

The level of GABAergic potentiation highly correlates with the ratio between the strength of convergent glutamatergic and GABAergic inputs. Our results suggest that glutamatergic input can take an active role in sculpting developing GABAergic connections.

\section{Differential induction mechanisms for GABAergic potentiation and depression}

We have identified two separate signaling pathways that can account for the potentiation and depression of GABAergic input. Depression is mediated by NMDA receptors located on the presynaptic GABAergic neurons. It has been suggested that highfrequency-stimulation-induced depression of GABAergic synapses is mediated by presynaptic NMDA receptors located at GABAergic terminals and that spilled glutamate from nearby glutamatergic terminals can activate these receptors (Lien et al., 2006). Although we observed a reduction of GABAergic release after induction of depression, which is consistent with a role of terminal NMDA receptors, we cannot exclude the possibility that NMDA receptors located on the dendrites of presynaptic GABAergic neurons mediate this effect. Especially considering that GABAergic neurons in the optic tectum also make dendrodendritic synapses (Streit et al., 1978), it is possible that activation of dendritic NMDA receptors on these neurons initiates a signaling cascade that directly leads to a change in release probability at 
A

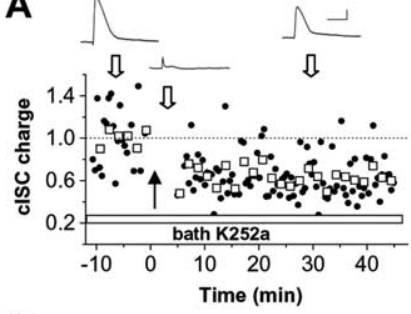

C

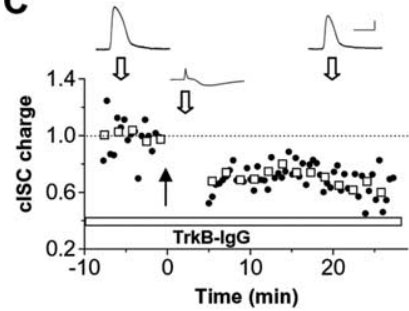

B

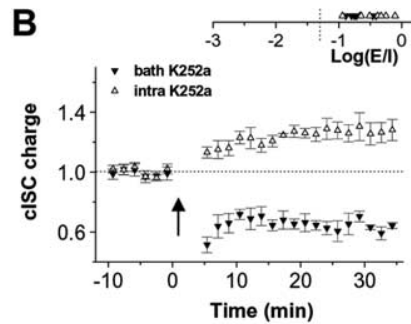

D

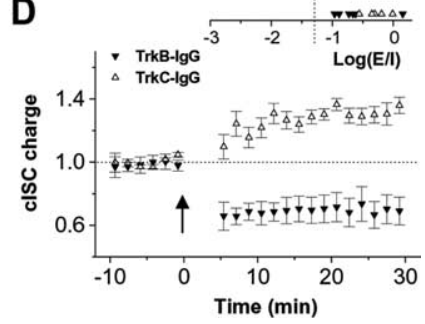

Figure 7. Presynaptic TrkB signaling is required for the induction of potentiation of CISC. $A$, An example experiment in which K252a was constantly present in the bath solution. Calibration: $50 \mathrm{pA} / 30 \mathrm{mV}, 400 \mathrm{~ms}$. $\boldsymbol{B}$, Summary of experiments in which K252a was applied in the bath solution (filled symbols; $n=5$ ) and those in which K252a was loaded into the postsynaptic cells (open symbols; $n=8$ ). The distribution of $\log (E / I)$ values in these experiments is shown in the inset. C, An example experiment in which the tadpole was preincubated with TrkB-lgG (2 $\mu \mathrm{g} / \mathrm{ml}$ ) for at least $1 \mathrm{~h}$. Calibration: $40 \mathrm{pA} / 20 \mathrm{mV}, 400 \mathrm{~ms}$. D, Summary of six experiments with TrkB-IgG (filled symbols) and five experiments with TrkC-lgG (open symbols) preincubation.

nearby dendrodendritic synapses. More detailed investigation is needed to test this possibility, which is beyond the scope of this study.

Potentiation, conversely, is induced through a postsynaptic mechanism, because blocking postsynaptic $\mathrm{Ca}^{2+}$ increase or postsynaptic NMDA receptors prevents its induction. Convergent glutamatergic input provides glutamate and membrane depolarization, the coincidence of which is required to activate NMDA receptors (Mayer et al., 1984; Nowak et al., 1984). The requirement of depolarization and glutamate release is supported by the results that, in the presence of strong glutamatergic input, hyperpolarizing current injection prevents the induction of GABAergic potentiation and that depolarizing the tectal cell with current injection alone fails to induce any change in GABAergic input. It is worth noting that we only measured the strength of AMPA receptor-mediated responses. Silent synapses are in fact present in this retinotectal system, and it is thought that developmental strengthening of glutamatergic synapses can be attributed to insertion of AMPA receptors to postsynaptic sites ( $\mathrm{Wu}$ et al., 1996). However, because AMPA/NMDA ratio in glutamatergic responses increases by $\sim 40 \%$ from stage 40 to 49 (Akerman and Cline, 2006) and the size of visually evoked AMPA responses increases by $\sim 14$-fold from stage 40 to 46 (Fig. $1 B$ ), the latter increase must be mainly attributed to a large increase in the number of glutamatergic synapses activated by visual input on a tectal cell. Therefore, visually evoked NMDA currents at stage 40 are likely much weaker than at stage 46 . This is supported by the result that, in cells with dominating GABAergic inputs, coupling visual conditioning with depolarizing current injection still induced depression of these inputs, consistent with the notion that some threshold level of glutamatergic input is required for potentiation.

In the present study, whole-cell recordings were used, which perturbed the intracellular $\mathrm{Cl}^{-}$concentration. As in other developing systems (Ben-Ari, 2002), neurons in the tectum exhibit a developmental shift in the $\mathrm{Cl}^{-}$equilibrium potential (supplemental Fig. 1, available at www.jneurosci.org as supplemental material). Therefore, at stages examined in this study, GABAergic currents can be depolarizing. Considering that depolarizing GABAergic currents facilitate NMDA receptor-mediated transmission (Akerman and Cline, 2006), the bona fide threshold of glutamatergic input strength for GABAergic potentiation is likely lower than reported in this study, although the basic conclusion still holds.

Our findings do not contradict a previous study in which only GABAergic depression was observed after repetitive visual stimuli (Lien et al., 2006). The latter study did not hold specific information on the strength of glutamatergic responses associated with the GABAergic inputs under examination or the age of tadpoles used, although we found that GABAergic plasticity is highly dependent on the strength of convergent glutamatergic input and developmental stage. In addition, because perforated patching was used in the previous study, any potential activity-dependent acute shift in the $\mathrm{Cl}^{-}$equilibrium potential (Woodin et al., 2003; Fiumelli et al., 2005) may have obscured the effect of potentiation of synaptic conductance.

\section{Heterosynaptic interaction and reversal of plasticity sign}

Because depression is induced presynaptically and repetitive stimuli alone are sufficient for its induction, synaptic depression tends to dominate plastic changes in GABAergic inputs to tectal cells. Indeed, it was always revealed when the induction of potentiation was prevented. Both depression and potentiation are associated with a change in presynaptic release: release probability and/or the number of functional release sites are reduced in the case of depression but increased in the case of potentiation. This suggests that depression and potentiation are two competing processes. Once the potentiation process is initiated, it can override the depression process. TrkB signaling plays an important role in this reversal of plasticity sign. We demonstrated that activation of TrkB receptors located at the presynaptic neurons is required for the induction of potentiation. BDNF, the highly expressed ligand of TrkB receptors in the brain, is likely to activate these receptors during the induction. Our data suggested a model of heterosynaptic modulation of GABAergic synapses by glutamatergic input: activation of NMDA receptors at glutamatergic synapses on tectal cell dendrites leads to $\mathrm{Ca}^{2+}$ influx, which may be further amplified; at early developmental stages, the postsynaptic $\mathrm{Ca}^{2+}$ increase can spread to larger dendritic domains (Tao et al., 2001); and $\mathrm{Ca}^{2+}$ increase leads to BDNF release by the postsynaptic cell, which acts on TrkB receptors at GABAergic terminals and initiates signaling that leads to an increase in evoked GABAergic release. Interestingly, only strongly activated GABAergic synapses can be potentiated by BDNF, suggesting that only those GABAergic synapses coactivated with glutamatergic input during visual stimuli are susceptible to BDNF effect. Such activity-dependent potentiation can be attributable to activity-dependent enhancement of TrkB tyrosine kinase activity (Nagappan and $\mathrm{Lu}, 2005$ ) and provides a mechanism for pathway-specific upregulation of GABAergic input. How TrkB signaling overrides the depressive signals generated in the presynaptic neuron remains to be further investigated.

\section{Implication for the functional development of GABAergic circuits}

The glutamatergic input-dependent bidirectional plasticity revealed in this study can modulate the development of GABAergic 
circuits in two ways. First, previous data have shown that GABAergic synapses in the tectum undergo a downregulation at early developmental stages, which is accompanied by the strengthening of glutamatergic synapses (Tao and Poo, 2005) (Fig. $1 B$ ). Recent evidence also shows that the number of $\mathrm{GABA}_{\mathrm{A}}$ receptors on the soma-proximal dendrites reduces with age in the mouse visual cortex (Katagiri et al., 2007). In view of different time courses for the development of GABAergic and glutamatergic synapses (i.e., GABAergic synapses are formed before glutamatergic synapses) (Tyzio et al., 1999; Ben-Ari, 2002), our data suggest that GABAergic synapses can be modulated by different plasticity processes at different maturation stages of the neuron. Shortly after RGC axons have arrived in the tectum, GABAergic synapses tend to undergo depression under visual stimulation. As glutamatergic inputs become much stronger, convergent and coincident GABAergic inputs can undergo potentiation, which will counteract the predominant depressive effect. Because the final plasticity effect depends on the ratio between the magnitudes of GABAergic and glutamatergic inputs, eventually a relatively stable ratio between these two inputs may be achieved, as reflected by a smaller variation in the $E / I$ ratio at mature stages (Fig. 2C).

Second, this bidirectional GABAergic plasticity may contribute to the formation of topographically identical excitatory and inhibitory receptive fields observed in mature brain circuits (Wehr and Zador, 2003; Zhang et al., 2003; Tan et al., 2004). Such identically tuned excitatory and inhibitory synaptic receptive fields can result from a progressive activity-dependent matching process (Tao and Poo, 2005). GABAergic plasticity observed in this study may serve as a potential synaptic mechanism underlying such receptive field matching. Because inhibitory inputs associated with strong excitatory inputs have a higher probability of undergoing potentiation and those associated with weak excitatory inputs have a higher tendency of being depressed, after repeated and separate activation of these inputs (e.g., through motion stimuli or retinal waves), the changes in their strengths will result in a better correlation with their associated excitatory inputs activated by a same stimulus.

Together, the glutamatergic input-dependent scaling of GABAergic synapses described in this study may engage in activity-dependent sculpting of inhibitory circuits during development and contribute to the formation of correlated or functionally balanced excitatory and inhibitory inputs.

B
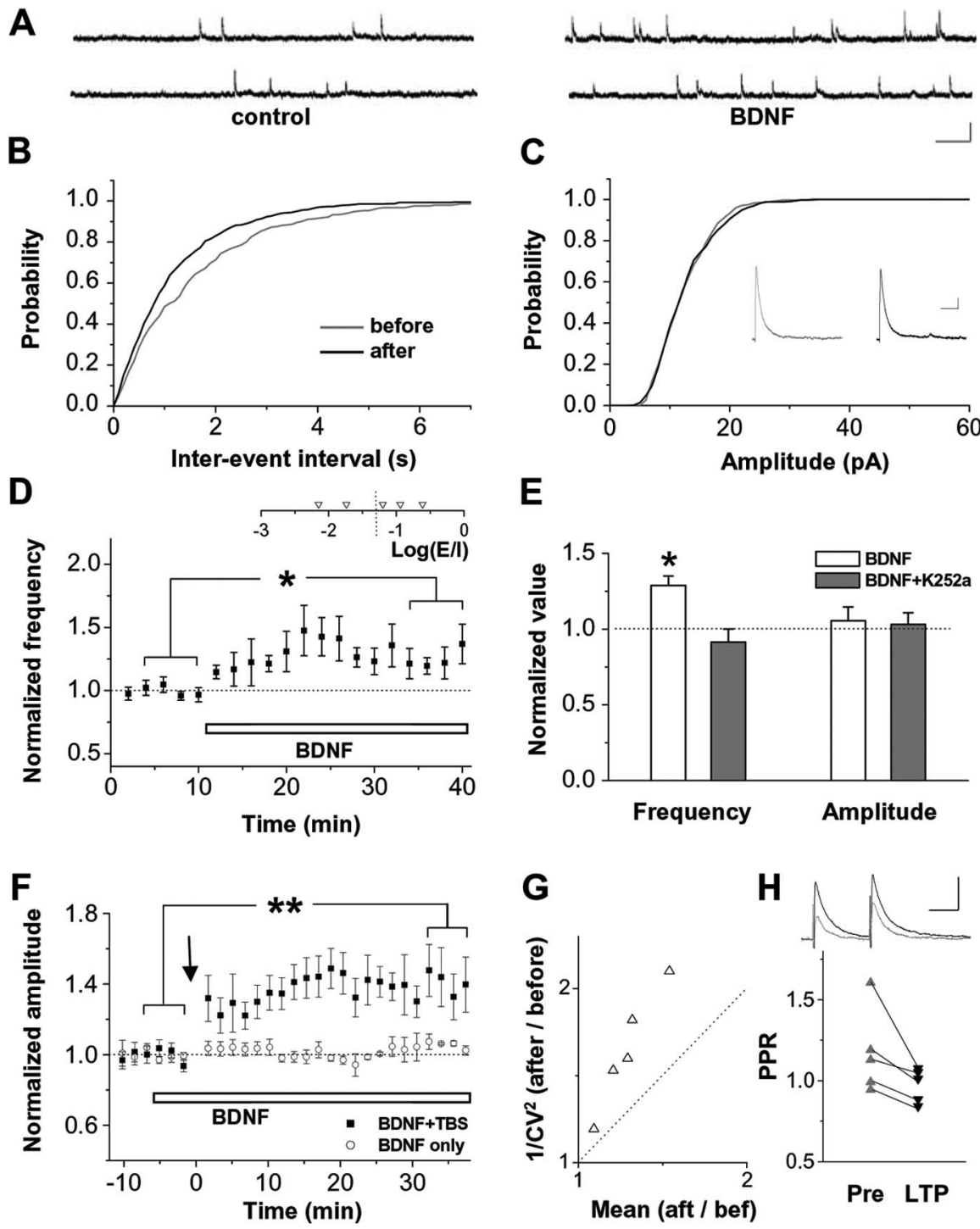

Figure 8. BDNF causes an increase in release at developing GABAergic synapses. $\boldsymbol{A}$, Top, Example traces of mIPSCs recorded during control period and $10 \mathrm{~min}$ after bath application of BDNF (100 ng/ml). Calibration: 10 pA, $500 \mathrm{~ms}$. B, C, Cumulative distribution of interevent intervals and amplitudes of mIPSCs recorded in 10 min sessions before and 10 min after BDNF application in the same cell as in $\boldsymbol{A}$. Insets in C are average mIPSCs (from 200 events) before and after BDNF application. Calibration: 2 pA, 50 ms. $D$, Average frequency of mIPSCs (normalized and binned with a 2 min bin size) during the course of experiments in which BDNF was applied after a $10 \mathrm{~min}$ control period $(n=5)$. The distribution of $\log (E / I)$ values for visually evoked responses in these cells is shown on the top. ${ }^{*} p<0.05$, paired $t$ test. $\boldsymbol{E}$, Normalized frequency and amplitude of mIPSC $10-20$ min after BDNF application in the normal bath solution (white bars; $n=5$ ) and in solution containing K252a (gray bars; $n=3$ ). ${ }^{*} p<0.02$. F, Circles, The amplitude of monosynaptic IPSCs (electrically evoked and recorded in the presence of CNQX) was not affected after the bath application of BDNF (white bar). Squares, When TBS was applied in the presence of BDNF, IPSCs were potentiated. ${ }^{* *} p<0.01$, paired $t$ test. $G, C V$ analysis for BDNF-facilitated long-term potentiation (LTP) of monosynaptic IPSCs. $\boldsymbol{H}$, PPR before $(1.17 \pm 0.11)$ and after $(0.97 \pm 0.04)$ BDNF-facilitated LTP ( $p=0.039$, one-tailed paired $t$ test). Top, Example traces for IPSC (average of 20) before (gray) and after (black) LTP. Calibration: 20 pA, 50 ms.

\section{References}

Aizenman CD, Manis PB, Linden DJ (1998) Polarity of long-term synaptic gain change is related to postsynaptic spike firing at a cerebellar inhibitory synapse. Neuron 21:827-835.

Akerman CJ, Cline HT (2006) Depolarizing GABAergic conductances regulate the balance of excitation to inhibition in the developing retinotectal circuit in vivo. J Neurosci 26:5117-5130.

Balkowiec A, Katz DM (2002) Cellular mechanisms regulating activitydependent release of native brain-derived neurotrophic factor from hippocampal neurons. J Neurosci 22:10399-10407. 
Ben-Ari Y (2002) Excitatory actions of gaba during development: the nature of the nurture. Nat Rev Neurosci 3:728-739.

Berretta N, Jones RS (1996) Tonic facilitation of glutamate release by presynaptic $\mathrm{N}$-methyl-D-aspartate autoreceptors in the entorhinal cortex. Neuroscience 75:339-344.

Broadie K, Bellen HJ, DiAntonio A, Littleton JT, Schwarz TL (1994) Absence of synaptotagmin disrupts excitation-secretion coupling during synaptic transmission. Proc Natl Acad Sci USA 91:10727-10731.

Caillard O, Ben-Ari Y, Gaiarsa JL (1999) Long-term potentiation of GABAergic synaptic transmission in neonatal rat hippocampus. J Physiol (Lond) 518:109-119.

Cohen-Cory S, Escandon E, Fraser SE (1996) The cellular patterns of BDNF and trkB expression suggest multiple roles for BDNF during Xenopus visual system development. Dev Biol 179:102-115.

Du JL, Poo MM (2004) Rapid BDNF-induced retrograde synaptic modification in a developing retinotectal system. Nature 429:878-883.

Engert F, Tao HW, Zhang LI, Poo M (2002) Moving visual stimuli rapidly induce direction sensitivity of developing tectal neurons. Nature 419:470-475.

Fiumelli H, Cancedda L, Poo MM (2005) Modulation of GABAergic transmission by activity via postsynaptic $\mathrm{Ca}^{2+}$-dependent regulation of KCC2 function. Neuron 48:773-786.

Gaiarsa JL, Caillard O, Ben-Ari Y (2002) Long-term plasticity at GABAergic and glycinergic synapses: mechanisms and functional significance. Trends Neurosci 25:564-570.

Geppert M, Goda Y, Hammer RE, Li C, Rosahl TW, Stevens CF, Sudhof TC (1994) Synaptotagmin I: a major $\mathrm{Ca}^{2+}$ sensor for transmitter release at a central synapse. Cell 79:717-727.

Gubellini P, Ben-Ari Y, Gaiarsa JL (2005) Endogenous neurotrophins are required for the induction of GABAergic long-term potentiation in the neonatal rat hippocampus. J Neurosci 25:5796-5802.

Haider B, Duque A, Hasenstaub AR, McCormick DA (2006) Neocortical network activity in vivo is generated through a dynamic balance of excitation and inhibition. J Neurosci 26:4535-4545.

Hartman KN, Pal SK, Burrone J, Murthy VN (2006) Activity-dependent regulation of inhibitory synaptic transmission in hippocampal neurons. Nat Neurosci 9:642-649.

Holmgren CD, Zilberter Y (2001) Coincident spiking activity induces longterm changes in inhibition of neocortical pyramidal cells. J Neurosci 21:8270-8277.

Huang ZJ, Kirkwood A, Pizzorusso T, Porciatti V, Morales B, Bear MF, Maffei L, Tonegawa S (1999) BDNF regulates the maturation of inhibition and the critical period of plasticity in mouse visual cortex. Cell 98:739-755.

Itami C, Kimura F, Nakamura S (2007) Brain-derived neurotrophic factor regulates the maturation of layer 4 fast-spiking cells after the second postnatal week in the developing barrel cortex. J Neurosci 27:2241-2252.

Jiang B, Huang ZJ, Morales B, Kirkwood A (2005) Maturation of GABAergic transmission and the timing of plasticity in visual cortex. Brain Res Rev 50:126-133.

Kano M, Rexhausen U, Dreessen J, Konnerth A (1992) Synaptic excitation produces a long-lasting rebound potentiation of inhibitory synaptic signals in cerebellar Purkinje cells. Nature 356:601-604.

Katagiri H, Fagiolini M, Hensch TK (2007) Optimization of somatic inhibition at critical period onset in mouse visual cortex. Neuron 53: 805-812.

Knusel B, Hefti F (1992) K-252 compounds: modulators of neurotrophin signal transduction. J Neurochem 59:1987-1996.

Komatsu Y (1996) $\mathrm{GABA}_{\mathrm{B}}$ receptors, monoamine receptors, and postsynaptic inositol trisphosphate-induced $\mathrm{Ca}^{2+}$ release are involved in the induction of long-term potentiation at visual cortical inhibitory synapses. J Neurosci 16:6342-6352.

Komatsu Y, Iwakiri M (1993) Long-term modification of inhibitory synaptic transmission in developing visual cortex. NeuroReport 4:907-910.

Lien CC, Mu Y, Vargas-Caballero M, Poo MM (2006) Visual stimuliinduced LTD of GABAergic synapses mediated by presynaptic NMDA receptors. Nat Neurosci 9:372-380.

Liu G (2004) Local structural balance and functional interaction of excitatory and inhibitory synapses in hippocampal dendrites. Nat Neurosci 7:373-379.
Llano I, Leresche N, Marty A (1991) Calcium entry increases the sensitivity of cerebellar Purkinje cells to applied GABA and decreases inhibitory synaptic currents. Neuron 6:565-574.

Lu YM, Mansuy IM, Kandel ER, Roder J (2000) Calcineurin-mediated LTD of GABAergic inhibition underlies the increased excitability of CA1 neurons associated with LTP. Neuron 26:197-205.

Maffei A, Nataraj K, Nelson SB, Turrigiano GG (2006) Potentiation of cortical inhibition by visual deprivation. Nature 443:81-84.

Manabe T, Wyllie DJ, Perkel DJ, Nicoll RA (1993) Modulation of synaptic transmission and long-term potentiation: effects on paired pulse facilitation and EPSC variance in the CA1 region of the hippocampus. J Neurophysiol 70:1451-1459.

Marino J, Schummers J, Lyon DC, Schwabe L, Beck O, Wiesing P, Obermayer K, Sur M (2005) Invariant computations in local cortical networks with balanced excitation and inhibition. Nat Neurosci 8:194-201.

Marty S, Berzaghi MdaP, Berninger B (1997) Neurotrophins and activitydependent plasticity of cortical interneurons. Trends Neurosci 20:198-202.

Mayer ML, Westbrook GL, Guthrie PB (1984) Voltage-dependent block by $\mathrm{Mg}^{2+}$ of NMDA responses in spinal cord neurones. Nature 309:261-263.

McLean HA, Caillard O, Ben-Ari Y, Gaiarsa JL (1996) Bidirectional plasticity expressed by GABAergic synapses in the neonatal rat hippocampus. J Physiol (Lond) 496:471-477.

Morishita W, Sastry BR (1996) Postsynaptic mechanisms underlying longterm depression of GABAergic transmission in neurons of the deep cerebellar nuclei. J Neurophysiol 76:59-68.

Nagappan G, Lu B (2005) Activity-dependent modulation of the BDNF receptor TrkB: mechanisms and implications. Trends Neurosci 28:464-471.

Nowak L, Bregestovski P, Ascher P, Herbet A, Prochiantz A (1984) Magnesium gates glutamate-activated channels in mouse central neurones. $\mathrm{Na}-$ ture 307:462-465.

Ouardouz M, Sastry BR (2000) Mechanisms underlying LTP of inhibitory synaptic transmission in the deep cerebellar nuclei. J Neurophysiol 84:1414-1421.

Patenaude C, Chapman CA, Bertrand S, Congar P, Lacaille JC (2003) $\mathrm{GABA}_{\mathrm{B}}$ receptor- and metabotropic glutamate receptor-dependent cooperative long-term potentiation of rat hippocampal $\mathrm{GABA}_{\mathrm{A}}$ synaptic transmission. J Physiol (Lond) 553:155-167.

Ross AH, McKinnon CA, Daou MC, Ratliff K, Wolf DE (1995) Differential biological effects of K252 kinase inhibitors are related to membrane solubility but not to permeability. J Neurochem 65:2748-2756.

Rybicka KK, Udin SB (1994) Ultrastructure and GABA immunoreactivity in layers 8 and 9 of the optic tectum of Xenopus laevis. Eur J Neurosci 6:1567-1582.

Salinas E, Sejnowski TJ (2000) Impact of correlated synaptic input on output firing rate and variability in simple neuronal models. J Neurosci 20:6193-6209.

Schinder AF, Poo M (2000) The neurotrophin hypothesis for synaptic plasticity. Trends Neurosci 23:639-645.

Schoch S, Deak F, Konigstorfer A, Mozhayeva M, Sara Y, Sudhof TC, Kavalali ET (2001) SNARE function analyzed in synaptobrevin/VAMP knockout mice. Science 294:1117-1122.

Schuman EM (1999) Neurotrophin regulation of synaptic transmission. Curr Opin Neurobiol 9:105-109.

Shadlen MN, Newsome WT (1994) Noise, neural codes and cortical organization. Curr Opin Neurobiol 4:569-579.

Shelton DL, Sutherland J, Gripp J, Camerato T, Armanini MP, Phillips HS, Carroll K, Spencer SD, Levinson AD (1995) Human trks: molecular cloning, tissue distribution, and expression of extracellular domain immunoadhesins. J Neurosci 15:477-491.

Shu Y, Hasenstaub A, McCormick DA (2003) Turning on and off recurrent balanced cortical activity. Nature 423:288-293.

Streit P, Knecht E, Reubi JC, Hunt SP, Cuenod M (1978) GABA-specific presynaptic dendrites in pigeon optic tectum: a high resolution autoradiographic study. Brain Res 149:204-210.

Tan AY, Zhang LI, Merzenich MM, Schreiner CE (2004) Tone-evoked excitatory and inhibitory synaptic conductances of primary auditory cortex neurons. J Neurophysiol 92:630-643.

Tao HW, Poo MM (2005) Activity-dependent matching of excitatory and inhibitory inputs during refinement of visual receptive fields. Neuron 45:829-836. 
Tao HW, Zhang LI, Engert F, Poo M (2001) Emergence of input specificity of ltp during development of retinotectal connections in vivo. Neuron 31:569-580.

Turrigiano GG, Nelson SB (2004) Homeostatic plasticity in the developing nervous system. Nat Rev Neurosci 5:97-107.

Turrigiano GG, Leslie KR, Desai NS, Rutherford LC, Nelson SB (1998) Activity-dependent scaling of quantal amplitude in neocortical neurons. Nature 391:892-896.

Tyzio R, Represa A, Jorquera I, Ben-Ari Y, Gozlan H, Aniksztejn L (1999) The establishment of GABAergic and glutamatergic synapses on CA1 pyramidal neurons is sequential and correlates with the development of the apical dendrite. J Neurosci 19:10372-10382.

Wang JH, Stelzer A (1996) Shared calcium signaling pathways in the induction of long-term potentiation and synaptic disinhibition in CA1 pyramidal cell dendrites. J Neurophysiol 75:1687-1702.
Wehr M, Zador AM (2003) Balanced inhibition underlies tuning and sharpens spike timing in auditory cortex. Nature 426:442-446.

Woodin MA, Ganguly K, Poo MM (2003) Coincident pre- and postsynaptic activity modifies GABAergic synapses by postsynaptic changes in $\mathrm{Cl}^{-}$ transporter activity. Neuron 39:807-820.

Wu G, Malinow R, Cline HT (1996) Maturation of a central glutamatergic synapse. Science 274:972-976.

Zhang LI, Tao HW, Holt CE, Harris WA, Poo M (1998) A critical window for cooperation and competition among developing retinotectal synapses. Nature 395:37-44.

Zhang LI, Tao H, Poo M (2000) Visual input induces long-term potentiation of developing retinotectal synapses. Nat Neurosci 3:708-715.

Zhang LI, Tan AY, Schreiner CE, Merzenich MM (2003) Topography and synaptic shaping of direction selectivity in primary auditory cortex. Nature 424:201-205. 